\title{
Characterization and Electrical Conductivity of Carbon-Coated Metallic (Ni, Cu, Sn) Nanocapsules
}

\author{
Dong Xing Wang, Asif Shah, Lei Zhou, Xue Feng Zhang, \\ Chun Jing Liu, Hao Huang, Xing Long Dong*
}

Key Laboratory of Materials Modification by Laser, Ion, and Electron Beams (Ministry of Education) and School of Materials Science and Engineering, Dalian University of Technology, Dalian 116024, China

\author{
*Correspondence to: \\ Dong XL, \\ Tel: +86-0411-84706130 \\ Fax: +86-0411-84709284 \\ E-mail: dongx|@dlut.edu.cn.
}

Received December 8, 2015 Revised December 11, 2015 Accepted December 14, 2015
Carbon-coated $\mathrm{Ni}, \mathrm{Cu}$ and $\mathrm{Sn}$ nanocapsules were investigated by means of X-ray diffraction (XRD), transmission electron microscopy (TEM) and a four-point probe device. All of these nanocapsules were prepared by an arc-discharge method, in which the bulk metals were evaporated under methane $\left(\mathrm{CH}_{4}\right)$ atmosphere. Three pure metals $(\mathrm{Ni}, \mathrm{Cu}$, $\mathrm{Sn}$ ) were typically diverse in formation of the carbon encapsulated nanoparticles and their different mechanisms were investigated. It was indicated that a thick carbon layers formed on the surface of $\mathrm{Ni}(\mathrm{C})$ nanocapsules, whereas a thin shell of carbon with 1 2 layers covered on $\mathrm{Cu}(\mathrm{C})$ nanocapsules, and the $\mathrm{Sn}(\mathrm{C})$ nanocapsules was, in fact, a longger multiwalled carbon nanotubes partially-filled with metal Sn. As one typical magnetic/dielectric nanocomposite particles, $\mathrm{Ni}(\mathrm{C})$ nanocapsules and its counterpart of oxide-coated $\mathrm{Ni}(\mathrm{O})$ nanocapsules were compared in the electrically conductive behaviors for further applications as the electromagnetic materials.

Key Words: Nanocapsules, Carbon, Metal, Core/shell, Eletric conductivity

\section{INTRODUCTION}

Research on nanomaterials has demonstrated that nanocapsules can have special characteristic compared to the bulk materials, largely due to their ultrafine size and high surface to volume ratio (Gleiter, 1989; Uyeda, 1991; Siegel, 1993). It is recognized that nanocapsules, which area bridge between the bulk and the atomic state, have novel characteristics for electrical, magnetic, and chemical properties. Besides the interest in understanding the nature and mechanisms of such new phenomena, there is a technologically driven force due to the immediate applications of these systems, such as catalysts, battery materials, color imaging, drug delivery systems, pigments in paints, magnetic tapes, ferrofluids, magnetic refrigerants, giant magnetoresistance (Hainfeld et al., 2006; McMahon et al., 2008; Guidelli et al., 2013), etc.

A wide range of techniques to fabricate nanophase materials has developed rapidly over the past decades (Charcosset et al., 2007; Chun et al., 2010). Such as laser ablation, combustion, arc-discharge, pyrolysis of polymeric precursors, melting solution, carbothermal reduction, and chemical vapor deposition. In a previous investigation, we developed a novel process to fabricate carbon-encapsulated magnetic nanocapsules by arc discharge in methane $\left(\mathrm{CH}_{4}\right)$ atmosphere, with a carbon rod as the cathode and a metal block as the anode (Shah et al., 2015; Shah et al., 2016). The discovery of the encapsulation of second phase materials into the cages from a composite system was significance for essentially two reasons (Ruoff et al., 1993; Seraphin et al., 1993; Tomita et al., 1993). First, the confinement of the cage provided the possibility of studying very small amounts of the encapsulant, potentially revealing novel properties that exist only on the nanoscale. Second, the protective graphitic cage of strong resistance against degradation promised applications such

This work was financially supported from National Natural Science Foundations of China (No. 51331006, 51271044 and 51171033).

(a) This is an open-access article distributed under the terms of the Creative Commons Attribution Non-Commercial License (http://creativecommons.org/licenses/by-nc/4.0) which permits unrestricted noncommercial use, distribution, and reproduction in any medium, provided the original work is properly cited.

Copyrights (c) 2015 by Korean Society of Microscopy 
as nanowires and suspensions of magnetic particles. Lots of studies (Seraphin et al., 1993; Guerret-Piecourt et al., 1994; Saito et al., 1994; Seraphin, 1995) revealed that not all materials introduced into the arc plasma from the composite target can form the encapsulated structures, which have been summarized in four categories. First, elements that can be encapsulated in the form of their carbides. Second, elements that are not encapsulated but to form carbon cages. Third, elements that form molecular carbides, competing with the carbon supply for the graphitic cage formation and suppressing them. Fourth, the ferromagnetic metals that stimulate catalytically growth of single-walled tubes and strings of spherical beads under a modified conditions of preparation (Dravid et al., 1995; Jiao et al., 1996).

In the present work, several typical carbon-coated metal nanocapsules, i.e., $\mathrm{Ni}(\mathrm{C}), \mathrm{Cu}(\mathrm{C})$ and $\mathrm{Sn}(\mathrm{C})$, were prepared by arc discharge method in the mixture atmosphere of methane and argon gases. The morphologies and formation mechanisms of these nanocapsulation structures were characterized and discussed. The electric conductivities of comparable $\mathrm{Ni}(\mathrm{C})$ nanocapsules and its counterpart of $\mathrm{Ni}(\mathrm{O})$ nanocapsules were measured. The effects of quite different shells of carbon and nickel oxide on electric conductivity were also emphasized.

\section{MATERIALS AND METHODS}

Using the same synthesis method of arc-discharge as in our previous work (Dong et al., 1998a), pure Ni, Cu, Sn bulk metals to be evaporated served as the anode, while a carbon rod served as the cathode. After the chamber was evacuated, methane gas was introduced and acted as a reactant gas during evaporation of $\mathrm{Ni}, \mathrm{Cu}$ and $\mathrm{Sn}$ bulks. The evaporating atmospheres for $\mathrm{Ni}(\mathrm{C}), \mathrm{Cu}(\mathrm{C})$ and $\mathrm{Sn}(\mathrm{C})$ nanocapsules are listed in Table 1. The distance between the two electrodes can be adjusted from outside of the chamber, so that the arc can be started and controlled for a continuous operation. $\mathrm{X}$-ray diffraction (XRD) was performed to identify the phases existing in the as-prepared nanopowders. The particles size and morphology was determined by analyzing transmission electron microscopy (TEM) micrographs. The asprepared nanopowders of $\mathrm{Ni}(\mathrm{C})$ and its counterpart of $\mathrm{Ni}(\mathrm{O})$ were compacted into round plates with $10 \mathrm{~mm}$ in diameter and about 0.3 to $0.5 \mathrm{~mm}$ in thickness. The electronic

Table 1. The preparation atmospheres for $\mathrm{Ni}(\mathrm{C}), \mathrm{Cu}(\mathrm{C})$, and $\mathrm{Sn}(\mathrm{C})$ nanocapsules

\begin{tabular}{ccc}
\hline Sample & $\mathrm{CH}_{4}(\mathrm{MPa})$ & $\operatorname{Ar}(\mathrm{MPa})$ \\
\hline $\mathrm{Ni}(\mathrm{C})$ & 0.0133 & - \\
$\mathrm{Cu}(\mathrm{C})$ & 0.0133 & - \\
$\mathrm{Sn}(\mathrm{C})$ & 0.01 & 0.02 \\
\hline
\end{tabular}

conductivities of both plates were measured under the stress pressures by a four-point probe device, then the relationship between conductivity of nanoparticles assembly and exoteric pressure was revealed.

\section{RESULTS AND DISCUSSION}

XRD patterns of the $\mathrm{Ni}(\mathrm{C}), \mathrm{Cu}(\mathrm{C})$ and $\mathrm{Sn}(\mathrm{C})$ nanocapsules are shown in Fig. 1 (Zhang et al., 2007; Liu et al., 2014). It is seen from Fig. 1 'a' and 'c' that no diffraction peaks of carbon or carbides occurred in $\mathrm{Ni}(\mathrm{C})$ and $\mathrm{Sn}(\mathrm{C})$ nanopowders indicating that no carbon assemblies with larger grain sizes existed in powders, nonetheless, a distinct peak of graphite is found in $\mathrm{Cu}(\mathrm{C})$ nanopowders (Fig. 1 ' $\mathrm{b}$ ') implying a bigger carbon phase may exist inside. The diffraction peak of graphite emerged at $2 \theta=26.7^{\circ}$ corresponds to (002) planes of its crystal lattice. All lattice constants of metal $(\mathrm{Ni}, \mathrm{Cu}$, $\mathrm{Sn})$ phases are the same with those of bulks. The diffraction peaks of $\mathrm{Ni}(\mathrm{C})$ nanopowders (Fig. 1 ' 'a') at $2 \theta=44.37^{\circ}, 51.75^{\circ}$, and $76.35^{\circ}$ are in accordance with the (111), (200) and (220) crystallographic planes of Ni (JCPDS No. 00-001-1258; Hull, 1921); the peaks at $2 \theta=43.48^{\circ}, 50.44^{\circ}$, and $74.13^{\circ}$ are of (111), (200) and (220) planes of Cu (JCPDS No. 00-001-124; Hanawalt et al., 1938); likewise, peaks at $2 \theta=30.78^{\circ}, 32.19^{\circ}$, and $45.12^{\circ}$ reflect the (200), (101) and (211) planes of Sn (JCPDS No. 01-086-2265; Lee \& Raynor, 1954).

In order to observe the morphologies and microstructures of all kinds of nanoparticles, the TEM with low and high magnifications were used to get the images of nanocapsules of $\mathrm{Ni}(\mathrm{C})$ (Fig. 2A and D), $\mathrm{Cu}(\mathrm{C})$ (Fig. 2B and E) and $\mathrm{Sn}(\mathrm{C})$ (Fig. $2 \mathrm{C}$ and $\mathrm{F})$. It is found that the $\mathrm{Ni}(\mathrm{C})$ nanocapsule is of an integrated carbon-coated particle with $\sim 15$ layers of graphitelike shell encapsulating the Ni core. The lattice planes of

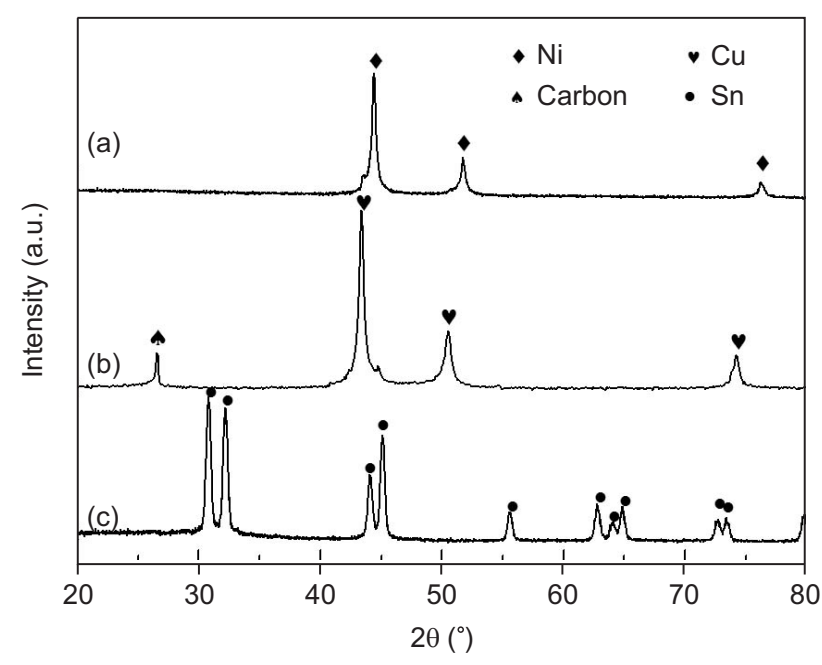

Fig. 1. X-ray diffraction patterns of the carbon-coated nanocapsules: (a) $\mathrm{Ni}(\mathrm{C})$; (b) $\mathrm{Cu}(\mathrm{C})$; and (c) $\mathrm{Sn}(\mathrm{C})$. 

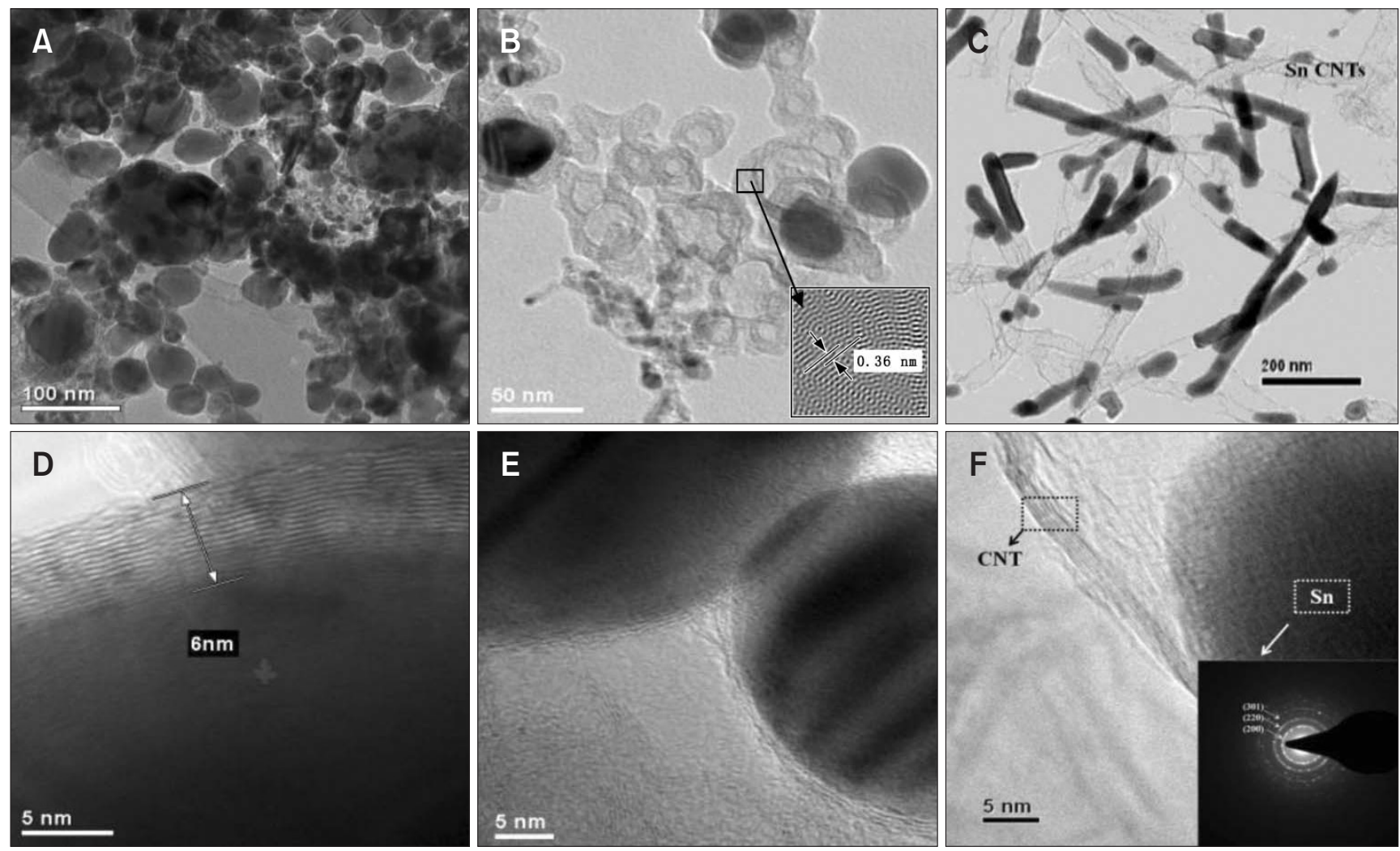

Fig. 2. Transmission electron microscopy (TEM) and high-resolution TEM images. (A, D) Ni(C) nanocapsules. (B, E) Cu(C) nanocapsules. (C, F) Sn(C) nanocapsules. CNTs, carbon nanotubes; inset in Fig. 2B, a Fourier transform image of the carbon cage; inset in Fig. 2F, the electron diffraction of Sn nanoparticles.

graphite is quite visible and the contiguous fringes around the Ni nanocrystal are good evidence for completes encapsulation by carbon layers. These nanocapsules are about 25 to $40 \mathrm{~nm}$ in diameter and the carbon protective shells are about 5 to 6 $\mathrm{nm}$ in thickness, corresponding to the (002) planes of crystal graphite phase. As shown in Fig. $2 \mathrm{~A}, \mathrm{Ni}(\mathrm{C})$ nanocapsules are spherical in shape and do not show any well-developed facets. One significant morphological characteristic to be noted from the image of Fig. 2D, is that neither gaps nor intermediate phases are observed between the outer carbon layer and the $\mathrm{Ni}$ core, which imply that the carbon atoms were released from the interior $\mathrm{Ni}$, i.e., a solid solution of $\mathrm{Ni}-\mathrm{C}$.

A dissimilar core/shell structure with respect to $\mathrm{Ni}(\mathrm{C})$ is found in $\mathrm{Cu}(\mathrm{C})$ nanocapsules as shown in Fig. 2B and E. A great amount of empty carbon cages exist in $\mathrm{Cu}(\mathrm{C})$ nanocapsules, indicating some of $\mathrm{Cu}$ cores have escaped from the carbon shells in formation of the nanocapsules which may be an evidence for $\mathrm{Cu}-\mathrm{C}$ solution with less carbon content than Ni-C solution. Moreover, from HRTEM image of Fig. 2E, it is clearly noted that the carbon shell on $\mathrm{Cu}(\mathrm{C})$ nanocapsules is so thin to be just 2 to 3 graphite layers with around 1 to $2 \mathrm{~nm}$ in thickness. It is different with the case of $\mathrm{Ni}(\mathrm{C})$ nanocapsules, e.g., the empty carbon cages and thin carbon layers, all come from the diversity between $\mathrm{Cu}$ and $\mathrm{Ni}$ metals in solubility of the carbon atoms. As can be seen, $\mathrm{Cu}(\mathrm{C})$ nanocapsules are spherical in shape, with the mean diameter ranging in 20 to $50 \mathrm{~nm}$. The lattice spacing of graphite shell is approximately close to that of the bulk graphite (002) planes, which is accordance with the previous results (Dong et al., 1998a, 1998b; Dong et al., 1999). No Cu carbide phase existed (detected by XRD profile) indicates the inner core is of metallic copper. The interface of core/shell is clearly distinguished and an inverse fast fourier transform image of the giant onion-like fullerenes is presented in the inset of Fig. 2B, where the lattice spacing corresponds to the graphite phase. Moreover, many lattice defects occur, such as collapses, unevenness and dislocations among the carbon shells.

Distinctive images of $\mathrm{Sn}(\mathrm{C})$ nanocapsules are presented in Fig. 2C and F. It is well shown, in fact, the $\mathrm{Sn}(\mathrm{C})$ nanocapsules are of Sn-filled carbon nanotubes (CNTs) with the average diameter of about $40 \mathrm{~nm}$ and 200 to $300 \mathrm{~nm}$ in length. The CNTs have multi walls of 5 to 7 graphene layers and are partially-occupied by Sn metal. The electron diffraction pattern of the as-synthesized Sn/CNTs is shown in the inset of Fig. $2 \mathrm{~F}$ which exhibits a pattern of poly-crystalline rings 


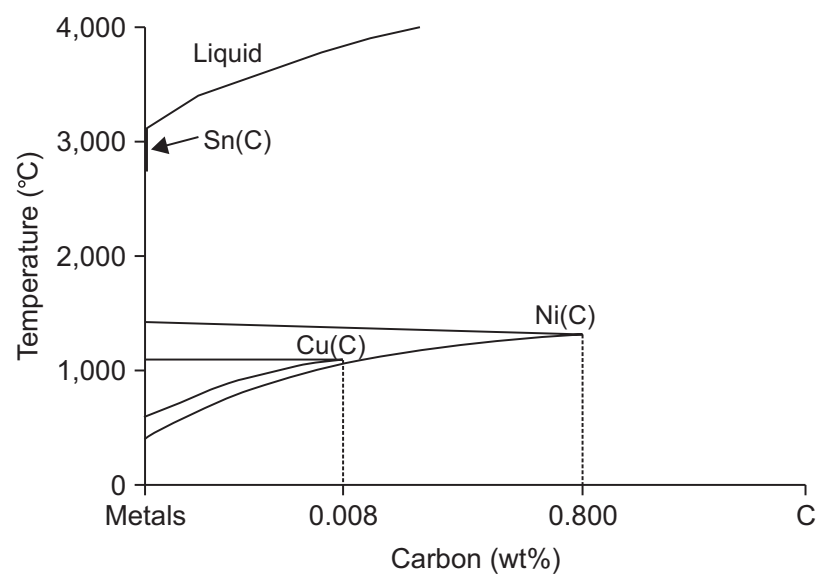

Fig. 3. Binary alloy phase diagram of metals-carbon.

assigning to the (200), (220), (301) planes of Sn. Such a structure of Sn-filled CNTs implies a weak combination between Sn and carbon atoms, in other word, the carbon is difficult to be dissolved in Sn substrate.

Gas-phase nucleation is the basis for a gas-to-solid conversion process. In this work, atoms of $\mathrm{Ni}, \mathrm{Cu}, \mathrm{Sn}$ were evaporated from the raw bulk with the assistance of high temperatures under arc plasma conditions. At the area of arc-discharge, the high temperature results in the decomposition of methane into hydrogen and carbon elements. Hydrogen atoms serve as a source of hydrogen plasma and carbon atoms act as reactant and condensation gas. Large thermal gradients were created between the hot arc and water-cooled walls of the chamber. The driving forces and nucleation energy were provided by supercooling and lead to a series of transitions. Generally, the atoms of metals and carbon can form a solid solution by random collisions, and subsequently continue until a supersaturated state is reached. Then, the nucleus forms and grows by the addition of monomer units. With the decline of temperature, the carbon is precipitated from solid solution in a supersaturated state and then form a coated layer on the solid, finally the core/shell structure is formed.

In this work, the metals of $(\mathrm{Ni}, \mathrm{Cu}, \mathrm{Sn})$ are typical to form the diverse carbon-coated core/shell nanocapsules, and their formation mechanisms can be understood in the binary alloy phase diagrams of $\mathrm{Ni}-\mathrm{C}, \mathrm{Cu}-\mathrm{C}$ and $\mathrm{Sn}-\mathrm{C}$, as shown in Fig. 3. It is shown that the solubility limit of $\mathrm{C}$ in $\mathrm{Ni}-\mathrm{C}$ solid solutions reaches $0.8 \mathrm{wt} \%$, in $\mathrm{Cu}-\mathrm{C}$ solid solution bacome $0.007 \mathrm{wt} \%$, nevertheless, the carbon absolutely can not be dissolved into $\mathrm{Sn}$ and no $\mathrm{Sn}-\mathrm{C}$ solid solution existed. It is obvious that the thickness of carbon layers on nanocapsules would be controlled by the solubility of $\mathrm{C}$ in a solid solution. More carbon atoms dissoved, thicker the carbon shells. The thickness of carbon layer on $\mathrm{Ni}(\mathrm{C})$ nanocapsule is about 5 to 6 $\mathrm{nm}$, typically reflecting a growth history of this nanocapsules (Saito et al., 1993), while only 1 to $2 \mathrm{~nm}$ thinckness of carbon

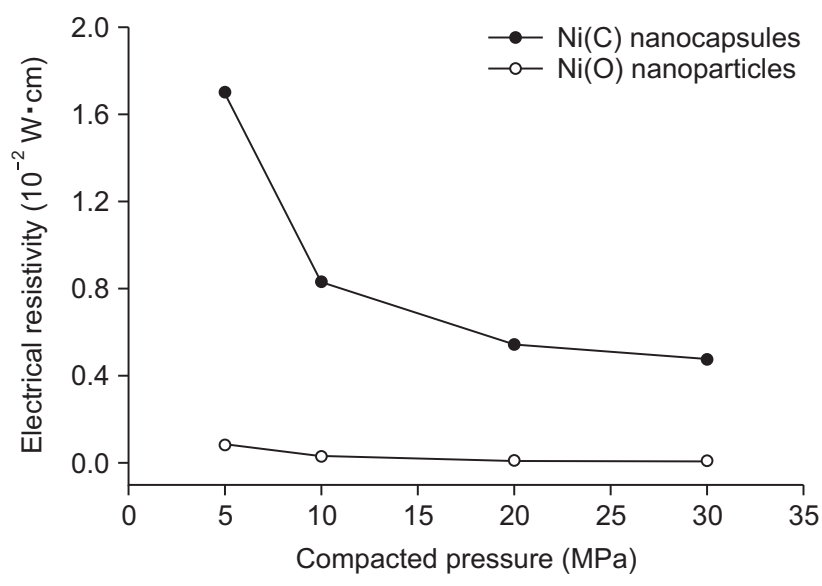

Fig. 4. Electrical resistivities of the compacted $\mathrm{Ni}(\mathrm{C})$ nanocapsules and $\mathrm{Ni}$ (O) nanoparticles, detected at different stress pressures.

layer is formed on the surface of $\mathrm{Cu}(\mathrm{C})$ nanocapsules and empty carbon cages are also created. It can be deduced that less carbon content in $\mathrm{Cu}-\mathrm{C}$ results in thin graphite shell and quite a hollow graphite ball. It is known from $\mathrm{Cu}-\mathrm{C}$ phase diagram that no copper carbide can be formed (Seraphin et al., 1996), that is, the metallic $\mathrm{Cu}$ cores are able to migrate out of their original cages in a solidification process and leave a mass of carbon cages behind. Because the carbon is greatly higher in melting point than Sn (Sn, $505 \mathrm{~K}$; C, 3,773 $\mathrm{K})$, so molten Sn will stay in a short time during the rapid solidification, meanwhile the catalysis of Sn (Zou \& Wang, 2011; Xu et al., 2013) can promote the free carbon phase isolated from each other, to grow carbon atoms along $\mathrm{sp}^{2}$ sites and form CNTs with the existance of liquid Sn (Lu et al., 2010). During the process, CNTs can adsorb the liquid Sn by the capillary force. As the temperature fall down to the melting point of $\mathrm{Sn}$, the liquid $\mathrm{Sn}$ inside tube wall will be shrunk and solidified, finally the structure of Sn-partially filled CNTs was shaped.

In order to study the effects of outer layers (shells) on electrical properties, the carbon-coated $\mathrm{Ni}(\mathrm{C})$ nanocapsules and nickle oxide-coated $\mathrm{Ni}(\mathrm{O})$ nanoparticles are chosen to measure their electrical resistivities. The resistivities of the compacted $\mathrm{Ni}(\mathrm{C})$ and $\mathrm{Ni}(\mathrm{O})$ nanopowders slices were detected using a four-point probe method. From Fig. 4, it is shown that both nanopowders samples exhibit a gradually decreased resistivity with increasing of stress pressure. The resistivities of $\mathrm{Ni}(\mathrm{C})$ nanocapsules are higher than those of $\mathrm{Ni}(\mathrm{O})$ nanoparticles, they are $4.7 \times 10^{-3} \Omega \cdot \mathrm{cm}$ and $5.5 \times 10^{-5}$ $\Omega \cdot \mathrm{cm}$ at $30 \mathrm{MPa}$, respectively. The intrinsic resistivity of bulk metal $\mathrm{Ni}$ is $7.0 \times 10^{-6} \Omega \cdot \mathrm{cm}$, which means the resistivity of $\mathrm{Ni}(\mathrm{C})$ nanocapsules slices is 1,000 times greater than $\mathrm{Ni}$ bulk and 100 times higher than $\mathrm{Ni}(\mathrm{O})$ nanoparticles. In our previous work, it had been proved that $\mathrm{Ni}(\mathrm{O})$ nanopaticles was coated by $\mathrm{Ni}_{2} \mathrm{O}_{3}$ shells with 2 to $3 \mathrm{~nm}$ in thickness (Dong 
et al., 1998a). The dielectric characters of $\mathrm{Ni}(\mathrm{C})$ nanocapsules had also been confirmed and investigated. It can be found from the TEM images of $\mathrm{Ni}(\mathrm{C})$, a mass of amorphous carbon with defections surround the Ni cores and would be main factors to affect the electrical conductivities.

\section{CONCLUSIONS}

The carbon-coated $\mathrm{Ni}(\mathrm{C}), \mathrm{Cu}(\mathrm{C})$ and $\mathrm{Sn}(\mathrm{C})$ nanocapsules were prepared by an arc-dischage method under methane $\left(\mathrm{CH}_{4}\right)$ atmosphere. $\mathrm{Ni}(\mathrm{C})$ nanocapsule is of an integrated carbon-coated particle with $\sim 15$ layers of graphite-like shell encapsulating the $\mathrm{Ni}$ core. $\mathrm{Cu}(\mathrm{C})$ nanocapsules have just 2 to 3 graphite layers on its surfaces and a geat deal of empty carbon cages. $\mathrm{Sn}(\mathrm{C})$ nanocapsules are of Sn-filled CNTs with the average diameter of about $40 \mathrm{~nm}$ and 200 to $300 \mathrm{~nm}$ in length. The CNTs have multi walls of 5 to 7 graphene layers. The electrical resistivity of compacted $\mathrm{Ni}(\mathrm{C})$ nanocapsules is about 1,000 times and 100 times higher than Ni bulk and compacted $\mathrm{Ni}(\mathrm{O})$ nanoparticles, respectivly. The defections in surrounded carbon shells would be main factors to affect the electrical conductivities of $\mathrm{Ni}(\mathrm{C})$ nanocapsules.

\section{CONFLICT OF INTEREST}

No potential conflict of interest relevant to this article was reported.

\section{REFERENCES}

Charcosset C, Bernard S, Fiaty K, Bechelany M, and Cornu D (2007) Membrane techniques for the preparation of nanomaterials: nanotubes, nanowires and nanoparticles: a review. Dyn. Biochem. Process Biotech. Mol. Biol. 1, 15-23.

Chun K Y, Youngseok O, Jonghyun R, Ahn J H, Kim Y J, Choi H R, and Seunghyun B (2010) Highly conductive, printable and stretchable composite films of carbon nanotubes and silver. Nature Nanotechnol. 5, 853-857.

Dong X L, Zhang Z D, Jin S R, and Kim B K (1999) Carbon-coated Fe$\mathrm{Co}(\mathrm{C})$ nanocapsules prepared by arc discharge in methane. J. Appl. Phys. 86, 6701-6706.

Dong X L, Zhang Z D, Jin S R, Sun W M, and Chuang Y C (1998a) Surface characterizations of ultrafine Ni particles. Nanostruct. Mater. 10, 585-592.

Dong X L, Zhang Z D, Jin S R, Sun W M, Zhao X G, and Chuang Y C (1998b) Characterization of ultrafine $y-\mathrm{Fe}(\mathrm{C}), \alpha$ arc-discharge in methane. $J$. Mater. Sic. 37, 1915-1919.

Dravid V P, Host J J, Teng M H, Elliott B, Hwang J, Johnson D L, Mason T O, and Weertman J R (1995) Controlled-size nanocapsules. Nature 374, 602.

Gleiter H (1989) Nanocrystalline materials. Prog. Mater. Sci. 33, 223315.

Guerret-Piecourt C, Bouar Y L, Loiseau A, and Pascard H (1994) Relation between metal electronic structure and morphology of metal compounds inside carbon nanotubes. Nature 372, 761-765.

Guidelli E J, Kinoshita A, Ramosand A, and Baffa O (2013) Silver nanoparticles delivery system based on natural rubber latex membranes. J. Nanopart. Res. 15, 1-9.

Hainfeld J F, Slatkin D N, Focella T M, and Smilowitz H M (2006) Gold nanoparticles: a new X-ray contrast agent. Brit. J. Radiol. 79, 248253.

Hanawalt J D, Rinn H W, and Frevel L K (1938) Chemical analysis by X-ray diffraction. Anal. Chem. 3, 475-512.

Hull A W (1921) X-ray crystal analysis of thirteen common metals. Phys. Rev. 17, 571.

Jiao J, Seraphin S, Wang X, and Withers J C (1996) Preparation and properties of ferromagnetic carbon coated $\mathrm{Fe}$, Co, and Ni nanoparticles. J. Appl. Phys. 80, 103-108.

Lee J A and Raynor G V (1954) The lattice spacings of binary tin-rich alloys. Proc. Phys. Soc. 67, 737-747.

Liu C J, Huang H, Cao G Z, Xue F H, Ramon P C, and Dong X L (2014) Enhanced electrochemical stability of Sn-carbon nanotube nanocapsules as lithium-ion battery anode. Electrochimica Acta 144, 376382.

Lu B, Huang H, Dong X L, and Lei J P (2010) Catalytic pyrogenation synthesis of $\mathrm{C} / \mathrm{Ni}$ composite nanoparticles: controllable carbon structures and high permittivities. J. Phy. D: Appl. Phys. 43, 105403105408.

McMahon S J, Mendenhall M H, Jainand S, and Currell F (2008) Radiotherapy in the presence of contrast agents: a general figure of merit and its application to gold nanoparticles. Phys. Med. Biol. 53, 5635-5651.

Ruoff R S, Lorents D C, Chan B, Malhotra R, and Subramoney S (1993) Single crystal metals encapsulated in carbon nanoparticles. Science 259, 346-348.

Saito Y, Okuda M, Yoshikawa T, Kasuya A, and Nishina Y (1994) Correlation between volatility of rare-earth metals and encapsulation of their carbides in carbon nanocapsules. J. Phys. Chem. 98, 66966698.

Saito Y, Yoshikawa T, Okuda M, Fujimoto N, Suzuki K, Kasuya A, and Nishina $Y$ (1993) Carbon nanocapsules encaging metals and carbides. J. Phy. Chem. Solids 54, 1849-1860.

Seraphin S (1995) Single-walled tubes and encapsulation of nanocrystals into carbon clusters. J. Electrochem. Soc. 142, 290-297.

Seraphin S, Zhou D, and Jiao J (1996) Filling the carbon nanocages. J. Appl. Phys. 80, 2097-2104.

Seraphin S, Zhou D, Jiao J, Withers J C, and Loutfy R (1993) Selective encapsulation of the carbides of yttrium and titanium into carbon nanoclusters. Appl. Phys. Lett. 63, 2073-2075.

Seraphin S, Zhou D, Jiao J, Withers J C, and Loutfy R (1993) Yttrium carbide in nanotubes. Nature 362, 503-503.

Shah A, Ding A, Wang Y H, Zhang L, Wang D X, Muhammad J, Huang H, 
Duan Y P, Dong X L, and Zhang Z D (2016) Enhanced microwave absorption by arrayed carbon fibers and gradient dispersion of Fe nanoparticles in epoxy resin composites. Carbon 96, 987-998.

Shah A, Wang Y H, Huang $H$, Zhang L, Wang D X, Zhou L, Duan Y P, Dong X L, and Zhang Z D (2015) Microwave absorption and flexural properties of Fe nanoparticle/carbon fiber/epoxy resin composite plates. Composite Struct. 131, 1132-1141.

Siegel R W (1993) Synthesis and properties of nanophase materials. Mater. Sci. Eng. A 168, 189-197.

Tomita M, Saito Y, and Hayashi T (1993) LaC2 encapsulated in graphite nano- particle. Jpn. J. Appl. Phys. 32, 280-282.
Uyeda R (1991) Studies of ultrafine particles in Japan: methods of preparation and technological applications. Prog. Mater. Sci. 35, 1-96.

Xu Y, Liu Q, Zhu Y, Liu Y H, Langrock A, Zachariah M R, and Wang C S (2013) Uniform nano-Sn/C composite anodes for lithium ion batteries. Nano Lett. 13, 470-474.

Zhang X F, Dong X L, Huang H, Wang D K, Lv B, and Lei J P (2007) High permittivity from defective carbon-coated $\mathrm{Cu}$ nanocapsules. Nanotechnology 18, 165-179.

Zou Y Q and Wang Y (2011) Sn@CNT nanostructures rooted in graphene with high and fast Li-storage capacities. ACS Nano 5, 8108-8114. 